\title{
Single-Run Separation of Closely Related Cationic and Anionic Com- pounds by CE-ESI-MS: Application to the Simultaneous Analysis of Melamine and its Analogs in Milk
}

\author{
Isabelle Kohler ${ }^{\mathrm{ab}}$, Emmanuelle Cognard ${ }^{\mathrm{bc}}$, Ivano Marchiic, Didier Ortelli ${ }^{\mathrm{bc}}$, Patrick Edder ${ }^{\mathrm{bc}}$, Jean- \\ Luc Veutheyab, Serge Rudaz ${ }^{\text {ab }}$, and Julie Schappler ${ }^{\star a b}$
}

\begin{abstract}
In recent years, two adulteration incidents concerning the addition of melamine, a nitrogen-rich industrial small polar compound, to pet food and infant formula products have occurred in China. These issues prompted laboratories to develop methods for the analysis of melamine and related compounds in a wide variety of food products and ingredients. In this context, a CE-ESI-MS method was developed to simultaneously analyze melamine and its related products (ammeline, ammelide and cyanuric acid) that possess close physico-chemical properties. This method allows the simultaneous analysis of both cations and anions in a single run, using CE to divide the run into two time segments in normal polarity mode. For this purpose, ESI polarity was switched once during the run, increasing sensitivity and data quality. The method was applied to spiked powdered milk and melamine-contaminated powdered milk, with two sample preparation procedures.
\end{abstract}

Keywords: CE-MS $\cdot$ Cyanuric acid $\cdot$ Food analysis $\cdot$ Melamine $\cdot$ Single run

\section{Introduction}

Melamine (MEL), 2,4,6-triamino-1,3,5triazine (Fig. 1), is an emerging contaminant that has been illegally added to dairy products such as milk, infant formula, and pet food. Adding MEL to food increases its nitrogen content, artificially boosting the protein level, especially when indirect protein assays based on total nitrogen are employed (Kjeldahl method). ${ }^{[1,2]}$ Commercially synthesized MEL can contain structural by-products, such as ammeline (AMLN), ammelide (AMLD), and cyanuric acid (CYA, Fig. 1). MEL is not metabo-

\footnotetext{
${ }^{*}$ Correspondence: Dr. J. Schappler ${ }^{\mathrm{ab}}$

Tel.: +41223796477

Fax: +41223796808

E-Mail: julie.schappler@unige.ch

aSchool of Pharmaceutical Sciences

University of Geneva, University of Lausanne

Bd d'Yvoy 20

$\mathrm{CH}-1211$ Geneva 4

bSwiss Centre for Applied Human Toxicology

University of Geneva

CMU, Rue Michel-Servet 1

$\mathrm{CH}-1211$ Geneva 4

cFood Authority Control of Geneva

Quai Ernest-Ansermet 22

CP 76

$\mathrm{CH}-1211$ Geneva 4
}

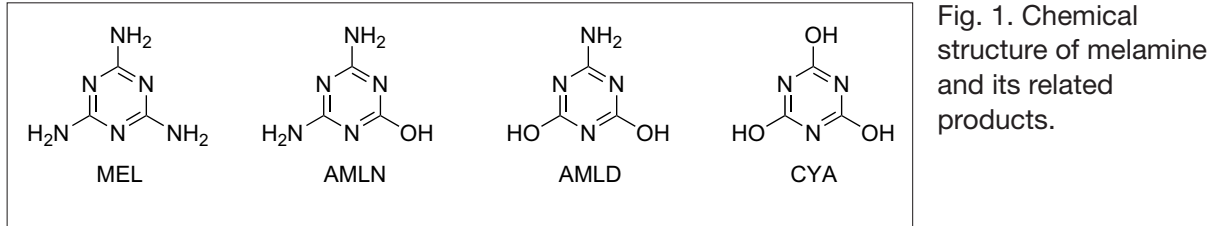

lized and is rapidly excreted in urine. Longterm exposure can reduce fertility and result in fetal toxicity. ${ }^{[2]}$ In addition, MEL and related triazines (particularly CYA) can form high molecular weight complexes through hydrogen bonding, leading to formation of insoluble crystals in kidneys and resulting in kidney stones and renal failure. ${ }^{[2-4]}$ Based on studies on rats, a tolerable daily intake (TDI) of $0.2 \mathrm{ppm}$ body weight was established for MEL and extrapolated to $1.5 \mathrm{ppm}$ body weight for CYA by the World Health Organization. Therefore, many countries have introduced limits for MEL in food products that provide a sufficient margin of safety related to the TDI, i.e. $1 \mathrm{ppm}$ in infant formula and $2.5 \mathrm{ppm}$ in other food.

Until now, the analytical methods developed to analyze MEL in food ${ }^{[5]}$ were enzyme-linked immunosorbent assay, ${ }^{[6]}$ enzyme immunoassay, ${ }^{[7]}$ surfaceenhanced Raman spectroscopy, ${ }^{[8]}$ GCMS, ${ }^{[9-11]}$ and LC-MS. ${ }^{[12-20]}$ Some of these methods also meet the growing need to detect MEL by-products because of their deleterious effects on health. ${ }^{[21-24]} \mathrm{CE}$ methods were also developed to analyze MEL with UV or MS detection. ${ }^{[25-34]}$ Capillary electrophoresis (CE) is a powerful separation technique for polar compounds with several advantages including high separation efficiency, low sample and solvent consumption, short analysis time, and simple instrumentation. UV-vis spectrophotometry is probably the most widely used detection technique due to the simplicity of the on-line configuration. However, this technique suffers from a lack of sensitivity because of the narrow optical path length allowed by the internal diameter of the capillary. Consequently, high analyte concentrations, which are rarely available in bioanalysis and food matrices, are required. To circumvent this lack of sensitivity, CE can be on-line coupled with mass spectrometry (MS). The latter is the preferred detection method for these applications due to its quasi-universality, high sensitivity, high selectivity, and ability to identify compounds in complex mixtures via mass-to-charge ratio $(\mathrm{m} / \mathrm{z})$. 
Electrospray ionization (ESI) is the most widespread ionization source used for hyphenating $\mathrm{CE}$ and $\mathrm{MS},{ }^{[35]}$ and two main configurations can be distinguished, either with or without the addition of a make-up liquid. The first approach is the most common, particularly with a coaxial sheath-flow interface. In this configuration, the sheath liquid mixes with the $\mathrm{CE}$ effluent at the tip of the separation capillary, providing electrical contact at the outlet end of the capillary, and the appropriate flow rate and solvent conditions for ionization and evaporation of the analytes. ${ }^{[36-38]}$

The main limitation of CE-ESI-MS concerns the use of volatile electrophoretic buffers (e.g. acetate, formate, carbonate, ammonium), and/or volatile selectivity modifiers to avoid the putative contamination of the ESI source. ${ }^{[39]}$ Conventionally, an acidic BGE, a sheath liquid containing formic or acetic acid, and ESI in the positive mode (ESI+) are used for cation analysis, while basic BGE and sheath liquid with ammonium are used for anion analysis in negative ESI mode (ESI-). Thus, simultaneous analysis of both cations and anions by CE-ESI-MS in a single run is not directly achievable and the capillary, the BGE, and the sheath liquid have to be adapted between applications. Several attempts were made by CE-UV to overcome this issue, using techniques such as complexing cations with EDTA in reversed polarity mode, ${ }^{40]}$ addition of poly(diallyldimethylammonium chloride) to the BGE, ${ }^{[41]}$ use of a coated capillary, ${ }^{[42]}$ and a dual-opposite injection approach, which consists of simultaneous injection from both sides of the capillary with the detector placed approximately in the center. ${ }^{[43-46]}$ However, these techniques can hardly be implemented when MS is used for detection. Therefore, it remains challenging to simultaneously analyze cations and anions by CE-ESI-MS. In the present paper, a CE-ESI-MS method is presented to allow the simultaneous detection of MEL, AMLN, AMLD, and CYA with adequate analytical conditions in a single run in spiked and contaminated powdered milk.

\section{Material and Methods}

\subsection{Chemicals}

Acetic acid, ammonia, hydrochloric acid, ammonium acetate, sodium hydroxide, ethanol (EtOH), formamide, $\mathrm{N}$-methylformamide (NMF), and N,Ndimethylformamide (DMF) of analytical reagent grade were obtained from Fluka (Buchs, Switzerland). Acetonitrile (ACN) and methanol $(\mathrm{MeOH})$ of analytical reagent grade were obtained from Panreac Quimica SA (Castella del Vallès, Spain), analytical grade isopropanol (iprOH) from

Table 1. Physico-chemical, electrophoretic, and MS properties of MEL and its related products.

\begin{tabular}{|c|c|c|c|c|}
\hline & MEL & AMLN & AMLD & CYA \\
\hline \multicolumn{5}{|c|}{ Physico-chemical properties } \\
\hline Molecular weight [Da] & 126.07 & 127.05 & 128.03 & 129.02 \\
\hline Acidic $\mathrm{pK}_{\mathrm{a}} \pm \mathrm{IC}_{95 \%}{ }^{\mathrm{a}}$ & - & $9.55 \pm 0.18$ & $6.97 \pm 0.09$ & $\begin{array}{l}6.89 \pm 0.06 \\
11.40 \pm 0.08\end{array}$ \\
\hline Basic $\mathrm{pK}_{\mathrm{a}} \pm \mathrm{IC}_{95 \%}{ }^{\mathrm{a}}$ & $5.12 \pm 0.04$ & $4.21 \pm 0.18$ & $1.58 \pm 0.11$ & - \\
\hline
\end{tabular}

\section{Electrophoretic properties}

lonization at pH $5.2 \quad 45 \%$ (cation) $\quad 9 \%$ (cation) $\quad 2 \%$ (anion) $2 \%$ (anion)

Mass spectrometry properties

$\begin{array}{lcclc}\text { Detected ions } & {[\mathrm{M}+\mathrm{H}]^{+}} & {[\mathrm{M}+\mathrm{H}]^{+}} & \begin{array}{l}{[\mathrm{M}-\mathrm{H}]^{-}} \\ {[2 \mathrm{M}-\mathrm{H}]^{-}}\end{array} & {[\mathrm{M}-\mathrm{H}]^{-}} \\ \mathrm{m} / \mathrm{z} & 127 & 128 & 127 & 128 \\ \text { Fragmentor voltage }[\mathrm{V}] & 140 & 140 & 255 & 90\end{array}$

${ }^{\text {ab }} \mathrm{pK}_{\mathrm{a}}$ values experimentally determined according to Geiser et al. ${ }^{[49]}$

Acros Organics (Geel, Belgium), and formic acid from Biosolve (Valkenswaard, Netherlands). Ultrapure water was supplied by a Milli-Q RG purification unit from Millipore (Bedford, MA, USA).

MEL, AMLN (atrazin-desethyl-desisopropyl-2-hydroxy), CYA were purchased from Sigma-Aldrich (Seelze, Germany), and AMLD was obtained from TCI Europe (Zwijndrecht, Belgium). They possess close physico-chemical properties (Fig. 1 and Table 1).

\subsection{Background Electrolyte and Sample Preparation}

2.2.1 BGE

The BGE consisted of a $25 \mathrm{mM}$ (ionic strength) ammonium acetate buffer set at $\mathrm{pH}$ 5.2. For confirmatory analysis of AMLD and CYA, a $25 \mathrm{mM}$ (ionic strength) ammonium acetate buffer set at $\mathrm{pH} 9.0$ was used. The $\mathrm{pH}$ values were measured with a SevenMulti pH meter (Mettler-Toledo, Schwerzenbach, Switzerland).

\subsubsection{Sample Preparation}

Stock standard solutions of the analytes were prepared by dissolving each reference compound in $\mathrm{MeOH}$ to obtain a concentration of $1 \mathrm{mg} / \mathrm{mL}$ (1000 ppm) for MEL and CYA, and $0.05 \mathrm{mg} / \mathrm{mL}$ (50 ppm) for AMLN and AMLD. Standard solutions at desired concentrations were prepared daily by diluting stock solutions in water.

The developed CE-ESI-MS method was tested with the following real samples: i) delipidated blank powdered milk Rapilait purchased from a local retailer store (Migros, Geneva, Switzerland), reconstituted as instructed on the packaging and spiked with MEL, AMLN, AMLD at 5 ppm, and CYA at $1 \mathrm{ppm}$ and ii) Chinese positive powdered milk provided from an interlaboratory study performed by the Food Authority Control of Geneva (Ge- neva, Switzerland) and reconstituted as required for this study.

A sample preparation procedure based on solid-phase extraction (SPE) was chosen to allow for the extraction of all compounds. Two different materials were studied: i) a new Strata Melamine cartridge from Phenomenex (Torrance, USA) which theoretically enables the simultaneous extraction of MEL and CYA and ii) a mixed-mode cation exchanger (MCX) Oasis cartridge from Waters (Milford, USA), used as the reference sample preparation procedure. [12,47]

\subsubsection{SPE with Strata Melamine}

Strictly following the manufacturer protocol, $100 \mu \mathrm{L}$ of $0.2 \mathrm{M} \mathrm{HCl}$ and $3 \mathrm{~mL}$ of ACN were added to $1 \mathrm{~mL}$ of reconstituted milk, vortexed, and centrifuged at $6000 \mathrm{rpm}$ for $10 \mathrm{~min}$. The supernatant was loaded onto the cartridge $(200 \mathrm{mg}$ sorbent, $3 \mathrm{~mL}$ ), previously conditioned with $3 \mathrm{~mL}$ of $\mathrm{MeOH}$ and $3 \mathrm{~mL}$ of water at 1 $\mathrm{mL} / \mathrm{min}$. The first washing step was performed with $1 \mathrm{~mL}$ of ACN-water (50:50, $\mathrm{v} / \mathrm{v}$ ) and the second with $500 \mu \mathrm{L}$ of $\mathrm{MeOH}-$ water $(50: 50, \mathrm{v} / \mathrm{v})$. The sorbent was dried for $2 \mathrm{~min}$ at $10 \mathrm{psi}$. The compounds were eluted with $500 \mu \mathrm{L}$ of $\mathrm{MeOH}$ and $1 \mathrm{~mL}$ of $\mathrm{MeOH}$-ammonia (95:5, v/v). The elution fraction was evaporated to dryness under a gentle steam of nitrogen and reconstituted with $1 \mathrm{~mL}$ ACN-20 mM ammonium acetate $(95: 5, \mathrm{v} / \mathrm{v})$, then injected into the CE-MS system.

\subsubsection{SPE with MCX}

Ten milliters of $0.12 \mathrm{M} \mathrm{HCl}$ were added to $5 \mathrm{~g}$ of reconstituted milk, and the mixture was vortexed for $45 \mathrm{~s}$ and centrifuged at $4000 \mathrm{rpm}$ for $5 \mathrm{~min}$. The supernatant was loaded onto the cartridge ( $150 \mathrm{mg}$ sorbent), which was previously conditioned with 5 $\mathrm{mL} \mathrm{MeOH}$ and $5 \mathrm{~mL}$ water at $1 \mathrm{~mL} / \mathrm{min}$. 
The washing step was done with $5 \mathrm{~mL}$ $0.1 \mathrm{M} \mathrm{HCl}$ and $2 \mathrm{~mL} \mathrm{MeOH}$. Compounds were eluted with $5 \mathrm{~mL} \mathrm{ACN}$-ammonia $(95: 5, \mathrm{v} / \mathrm{v})$. One $\mathrm{mL}$ of the elution fraction was evaporated to dryness under a gentle steam of nitrogen and reconstituted with $1 \mathrm{~mL}$ ACN-20 mM ammonium acetate (95:5, v/v), then injected into the CE-MS system.

\subsection{Instrumentation}

\subsubsection{Capillary Electrophoresis}

CE experiments were performed with an $\mathrm{HP}{ }^{3 \mathrm{D}} \mathrm{CE}$ system from Agilent (Waldbronn, Germany) equipped with an oncapillary diode array detector, an autosampler, and a power supply able to deliver up to $30 \mathrm{kV}$. Separation was performed using a fused-silica capillary (BGB Analytik AG, Böckten, Switzerland) with a total length of $80 \mathrm{~cm}$ and an internal diameter of 50 $\mu \mathrm{m}$. Before its first use, the capillary was rinsed sequentially at 2 bar with $\mathrm{MeOH}$ (6 min), water (3 min), $0.1 \mathrm{M} \mathrm{NaOH}$ (6 min), water (3 min), $0.1 \mathrm{M} \mathrm{HCl}$ (6 min), water (3 min), and BGE (6 min). The capillary was conditioned daily with $\mathrm{MeOH}$ and water at 2 bar (3 min each). Prior to each sample injection, the capillary was rinsed at 2 bar with fresh BGE (2 min). When not in use, the capillary was rinsed with water and then dry-stored. Samples were kept at ambient temperature in the autosampler and injected hydrodynamically at 50 mbar for $25 \mathrm{~s}$ (corresponding to $1.7 \%$ of the capillary length). Experiments were carried out in positive polarity mode (anode at the inlet and cathode at the outlet). A constant voltage of $30 \mathrm{kV}$ with an initial ramping of $1667 \mathrm{~V} / \mathrm{s}$ (18 s) was applied, and the capillary was thermostated at $25^{\circ} \mathrm{C}$.

\subsubsection{Mass Spectrometry}

MS detection was performed with a single quadrupole Agilent Series 1100 MSD (Palo Alto, CA, USA). The electrospray ionization was carried out sequentially in positive and negative modes with time segments. A CE-MS adapter kit interface from Agilent was used to interface the $\mathrm{HP}{ }^{3 \mathrm{D}} \mathrm{CE}$ instrument with the mass spectrometer. The composition of the coaxial sheath liquid was a mixture of iprOH-water-ammonia (50:50:2, v/v) containing $25 \mathrm{mM}$ acetic acid. The sheath liquid was delivered by a Jasco PU-980 HPLC Pump (Omnilab, Mettmenstetten, Switzerland) at $3 \mu \mathrm{L} / \mathrm{min}$. The ESI capillary voltage was set at $4300 \mathrm{~V}$ in the positive mode and $3400 \mathrm{~V}$ in the negative mode. The nebulizing pressure and drying gas flow rate were set at 4 psi and 4 $\mathrm{L} / \mathrm{min}$, respectively, while the drying gas temperature was set at $250{ }^{\circ} \mathrm{C}$. These values were selected according to Geiser et $a l .{ }^{[48]}$ In preliminary experiments, MEL, AMLN, AMLD were infused at $50 \mathrm{ppm}$ each, and CYA at $250 \mathrm{ppm}$ in the BGE to determine their optimal fragmentor values, resulting in the highest intensity for the most abundant ions (Table 1).

\section{4 pKa Determination}

Given the numerous predictive $\mathrm{pK}$ values found in the literature for the four compounds, experimental $\mathrm{pK}_{\mathrm{a}}$ values were determined by CE-UV using a dynamic coating procedure. ${ }^{[49]}$ Knowing accurate $\mathrm{pK}_{\mathrm{a}}$ values allowed the best $\mathrm{pH}$ value for $\mathrm{BGE}$, at which all the compounds were partially ionized, to be selected. Because the $\mathrm{pK}_{\mathrm{a}}$ value depends on BGE ionic strength and temperature, the values used were calculated for $25 \mathrm{mM}$ and $25^{\circ} \mathrm{C}$.

\subsection{Software}

BGEs were prepared with the help of PHoEBuS software (version 1.3, Analis, Namur, Belgium). CE ChemStation (version B.01.03, Agilent, Waldbronn, Germany) was used for instrument control, data acquisition, and data handling. Prism software (version 4.0, GraphPad Software, San Diego, CA, USA) was used to determine $\mathrm{pK}_{\mathrm{a}}$ values using experimental electrophoretic mobilities at different $\mathrm{pH}$ values.

\section{Results and Discussion}

\subsection{Development of Analytical Conditions}

All compounds present similar structures and therefore have close physicochemical properties (Fig. 1 and Table 1). Hence, the challenge was to find BGE conditions able to separate compounds according to their molecular size or ionization percentage. $\mathrm{pK}$ Values can aid in the choice of buffer $\mathrm{pH}$ to obtain the best selectivity. Predicted $\mathrm{pK}$ values were 5.6 \pm 0.2 (basic) for MEL, $4.0 \pm 0.2$ (basic) and $6.2 \pm 0.7$ (acid) for AMLN, $1.5 \pm 0.7$ (basic) and $6.8 \pm 0.7$ (basic) for AMLD, and $5.2 \pm 0.2$ (acid) for CYA. Because theoretical $\mathrm{pK}_{\mathrm{a}}$ values were not accurate, they were experimentally determined for the four compounds.

\subsection{1 pKa Determination and BGE Conditions}

Results obtained from experimental $\mathrm{pK}$ determination, as described by Geiser et a l., $^{[49]}$ are summarized in Table 1 . The selection of a BGE that allowed electrophoretic separation between the four analytes at a $\mathrm{pH}$ value in which all compounds were ionized was then performed. Conventionally, MEL and AMLN (possessing basic $\mathrm{pK}$ values) can be separated as cations under acidic conditions $(\mathrm{pH}<6)$, whereas AMLD and CYA (possessing acidic $\mathrm{pK}_{\mathrm{a}}$ values) can be analyzed as anions in neutral or basic conditions $(\mathrm{pH}>6)$.
Numerous BGEs were tested, including 25-100 $\mathrm{mM}$ ammonium acetate and ammonium formate buffers between $\mathrm{pH}$ 4.0-7.0, in steps of 0.25 . The influence of organic solvent addition was also investigated because it might allow selectivity changes. Furthermore, the presence of an organic solvent may i) enhance peak efficiency, ii) be more easily evaporated for ESI-MS detection, and iii) increase sensitivity. ${ }^{[50]}$ Six different organic modifiers were tested: $\mathrm{MeOH}$, EtOH, ACN, formamide, NMF, and DMF, added from 10 to $50 \%(\mathrm{v} / \mathrm{v})$ to the BGE. Pure non-aqueous conditions were also investigated but did not lead to separative improvement regardless of the nature of the organic solvent or its concentration in the BGE. In summary, all compounds were partially ionized in a $25 \mathrm{mM}$ (ionic strength) ammonium acetate buffer set at $\mathrm{pH} 5.2$ (Table 1). Under these conditions, MEL and AMLN were separated and migrated as cations before the EOF, whereas AMLD and CYA co-migrated as anions after the EOF (Fig. 2).

\subsubsection{Interface and MS Conditions}

To obtain a stable and repeatable spray in the ESI source, interface parameters, such as ESI voltage and sheath liquid composition, were evaluated. Applied voltages were set at $4300 \mathrm{~V}$ and $3400 \mathrm{~V}$ in ESI+ and ESI-, respectively, to allow good ionization with stable ESI currents. The sheath liquid was an iprOH-water mixture that afforded electrical connection to close the CE circuit and evaporation of CE effluent at the tip of the capillary. ${ }^{[37,48,51]}$

Conventionally, a small percentage of acid is added to the hydro-organic mixture for basic compounds ionization (e.g. formic acid, TFA) to assist analyte protonation, and a small amount of ammonia is added to increase deprotonation of acidic compounds. To analyze MEL and its byproducts, a sheath liquid composed of a mixture of water-iprOH $(50: 50, \mathrm{v} / \mathrm{v})$ with ammonia was investigated to allow simultaneous protonation of MEL and AMLN and deprotonation of AMLD and CYA. Ammonia has the ability to deprotonate acidic analytes while providing a proton to basic compounds, allowing all the analytes to be ionized. ${ }^{[52,53]}$ Its concentration was varied to obtain a compromise between analyte sensitivity and spray stability, which was achieved at $2 \%(\mathrm{v} / \mathrm{v})$. Acetic acid of $25 \mathrm{mM}$ concentration was also added to the sheath liquid to stabilize CE and ESI currents and reduce baseline fluctuations in the positive and negative modes. Optimized fragmentor voltages, which resulted in the highest intensity for all compounds, were set at $140 \mathrm{~V}$ for MEL and AMLN, and $90 \mathrm{~V}$ for AMLD and CYA. 


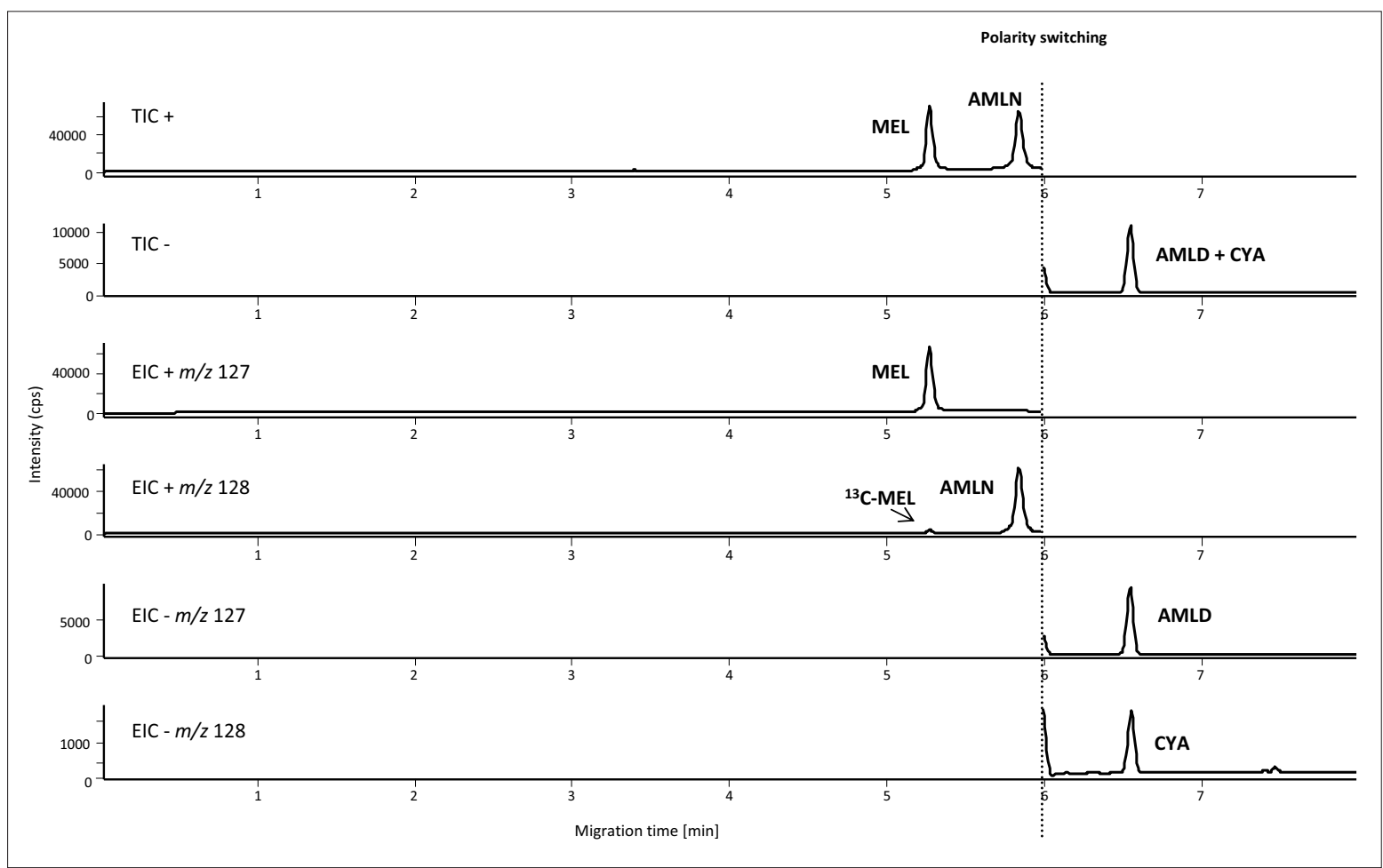

Fig. 2. CE-ESI-MS electropherograms obtained at $\mathrm{pH}$ 5.2 by injecting a mixture of MEL, AMLN, AMLD, and CYA at $25 \mathrm{ppm}$ (each in water). ESI+ from 0 to $6.0 \mathrm{~min}$, switch of polarity at $6.0 \mathrm{~min}$ (300 ms), and ESI- from 6.3 to $8 \mathrm{~min}$. See text for experimental conditions.

\subsubsection{Acquisition Mode}

To achieve a simultaneous MS detection of cations and anions within a single run, ESI polarity can be switched throughout the entire run and simultaneous ESI+/signals can be monitored. However, this might induce a loss in sensitivity attributable to the time necessary to perform polarity switching. Moreover, this could also imply a loss in data quality because the cycle time would greatly increase in simultaneous ESI+/- mode compared to single ESI mode, resulting in low acquisition rates. ${ }^{[53]}$ Because it is important to maintain at least 15 acquisition points per peak for quantitative purpose, this could be barely possible with the narrow peak width obtained in CE ( $c a .6 \mathrm{~s}$ ). Using the unique feature of zone electrophoresis that allows separation between cationic compounds in the first run segment and anionic compounds in the second, the division of the run into two time segments for MS acquisition was considered. Consequently, ESIMS responses were obtained in a single polarity mode (i.e. one recorded TIC trace, either ESI+ or ESI-), giving more sensitive results. From the beginning of the run to the polarity switch, a first window corresponding to the migration of cationic com- pounds was monitored in positive mode, and two ions were detected, $\mathrm{m} / \mathrm{z}, 127$ and 128 , corresponding to $[\mathrm{M}+\mathrm{H}]^{+}$of $\mathrm{MEL}$ and AMLN, respectively. From the switch to the end of the run, a second window corresponding to the anionic species was monitored in negative mode and ions $\mathrm{m} / \mathrm{z}$ 127 and 128 were detected, corresponding to $[\mathrm{M}-\mathrm{H}]^{-}$of AMLD and CYA, respectively. The time of the polarity switch was determined each day by injecting an EOF marker prior to analyses. The marker was also injected every five runs to correct the time of the switch because of EOF migration time variability. It should be noted

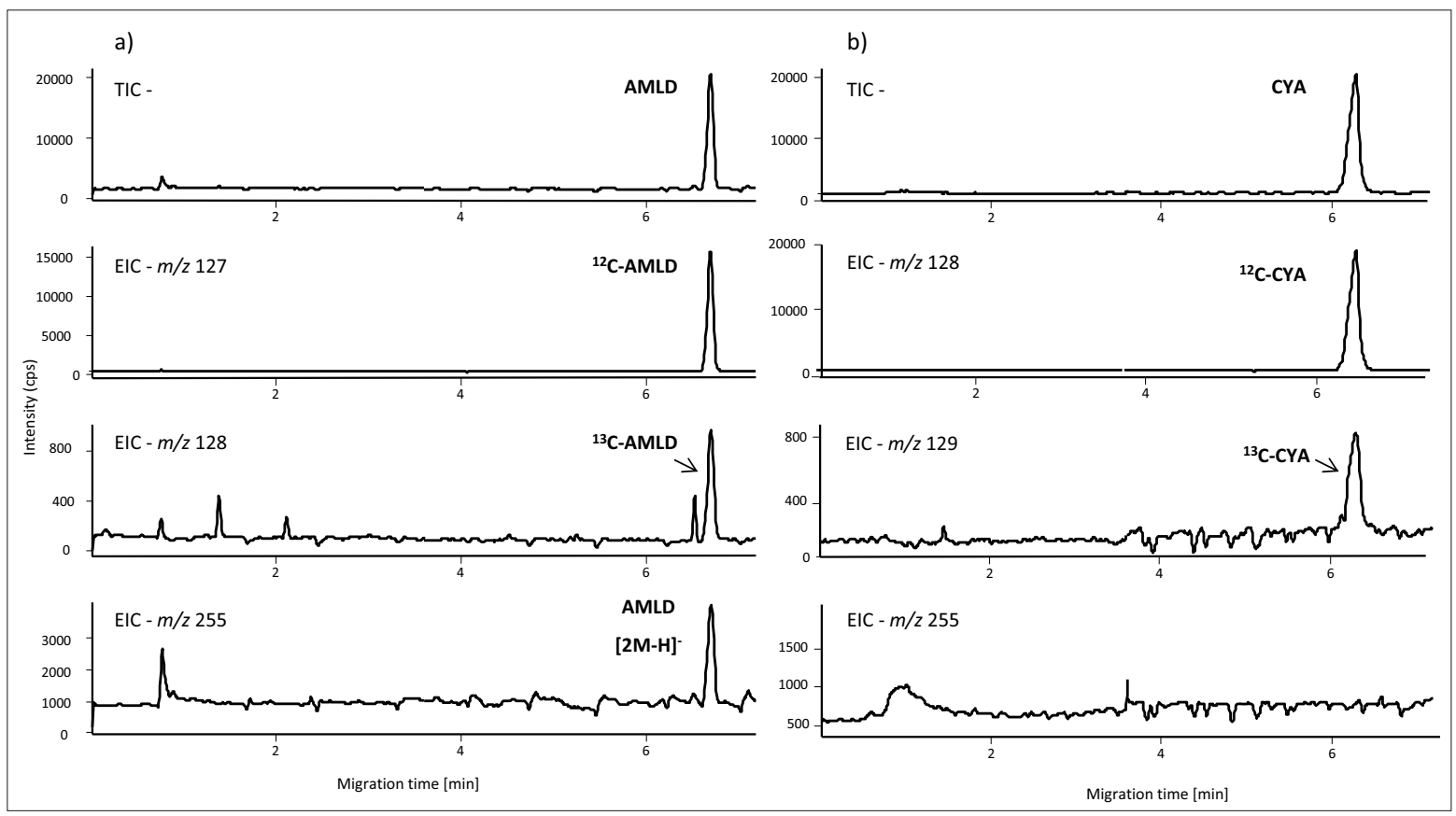

Fig. 3. a) CE-ESI-MS electropherograms obtained in ESI- at pH 5.2 by injecting AMLD at $25 \mathrm{ppm}$ in water. b) CE-ESI-MS electropherograms obtained in ESI- at pH 5.2 by injecting CYA at $25 \mathrm{ppm}$ in water. See text for experimental conditions. 
that the switch between both polarities was achieved in $300 \mathrm{~ms}$. Under these conditions, the limits of detection (LOD), corresponding to a signal-to-noise ratio $(\mathrm{S} / \mathrm{N})$ of 3, were $200 \mathrm{ppb}$ for MEL, AMLD, CYA, and $500 \mathrm{ppb}$ for AMLD.

An important issue concerned the limited spectral resolution of the single quadrupole mass spectrometer $(\mathrm{m} / \mathrm{z}, 0.7$ FWHM) that did not permit straightforward MS discrimination due to the small $\mathrm{m} / \mathrm{z}$ difference between the analytes. This was not critical for cations because the electrophoretic selectivity between MEL and AMLN allowed their physical separation despite the putative interference of MEL on AMLN MS-trace due to ${ }^{13} \mathrm{C}$ isotopic contribution of MEL (Fig. 2). However, the resolution was insufficient for anions; AMLD and CYA were not separated by either CE or MS because of the ${ }^{13} \mathrm{C}$-isotopic contribution of AMLD on CYA MS-trace. MS spectra of both compounds performed in scan mode between mass range $m / z, 100-1000$ revealed the presence of the AMLD dimer form [2M$\mathrm{H}^{-}$at $m / z 255$. The latter was thus included as a confirmatory ion for AMLD identification (Fig. 3). When in doubt, other operating conditions could be performed with a BGE at basic pH in ESI- mode with the same sheath liquid composition. For example, a $25 \mathrm{mM}$ (ionic strength) ammo-

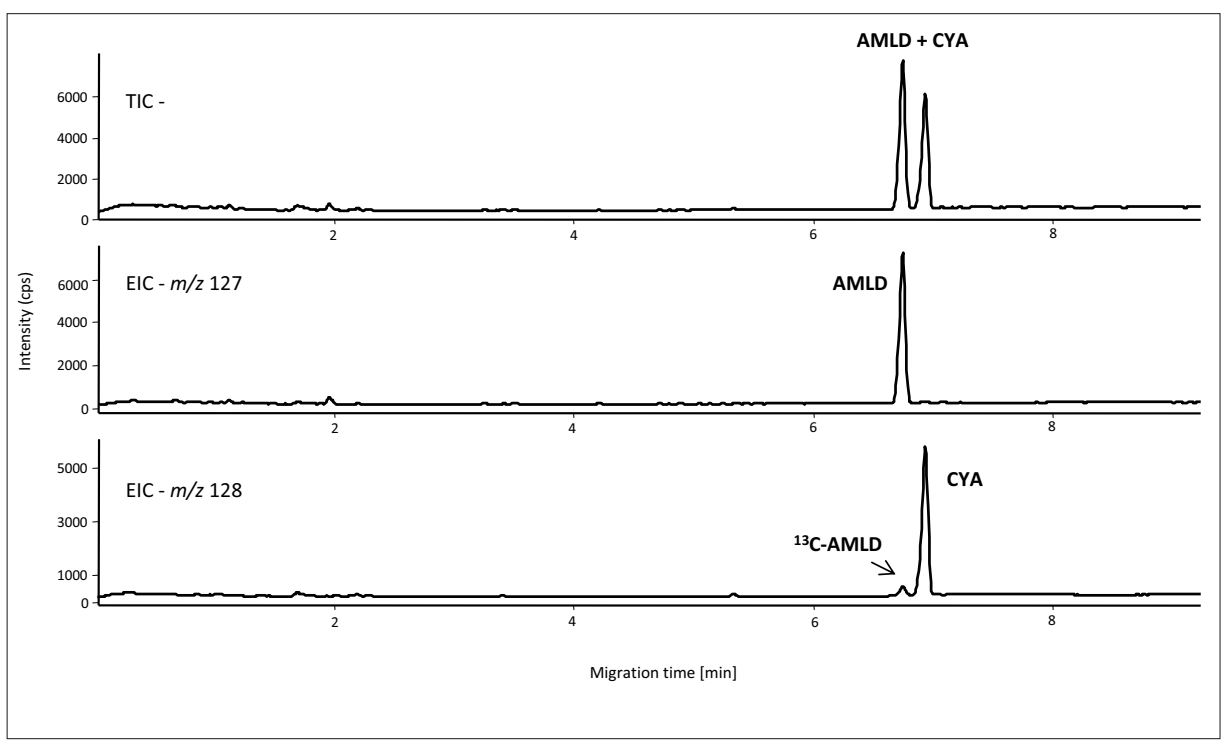

Fig. 4. CE-ESI-MS electropherograms obtained in ESI- at pH 9.0 by injecting a mixture of AMLD and CYA at 25 ppm (each in water). See text for experimental conditions.

nium acetate $\mathrm{BGE}$ set at $\mathrm{pH} 9.0$ allowed a complete electrophoretic separation of AMLD and CYA (Fig. 4).

\subsection{Application to Real Samples}

A new cartridge was introduced on the market that would allow the simultaneous extraction of both MEL and CYA via strong cationic exchange and hydrophilic lipophilic interactions, and was tested for
MEL and its by-products. The protocol developed by the manufacturer was strictly followed for the extraction of Rapilait milk spiked with the four analogs. Results are shown in Fig. 5a and were not satisfactory in terms of peak shape for MEL and AMLN, whereas AMLD and CYA were absent on the electropherogram. To confirm the previous results, this material was evaluated with aqueous standard solutions

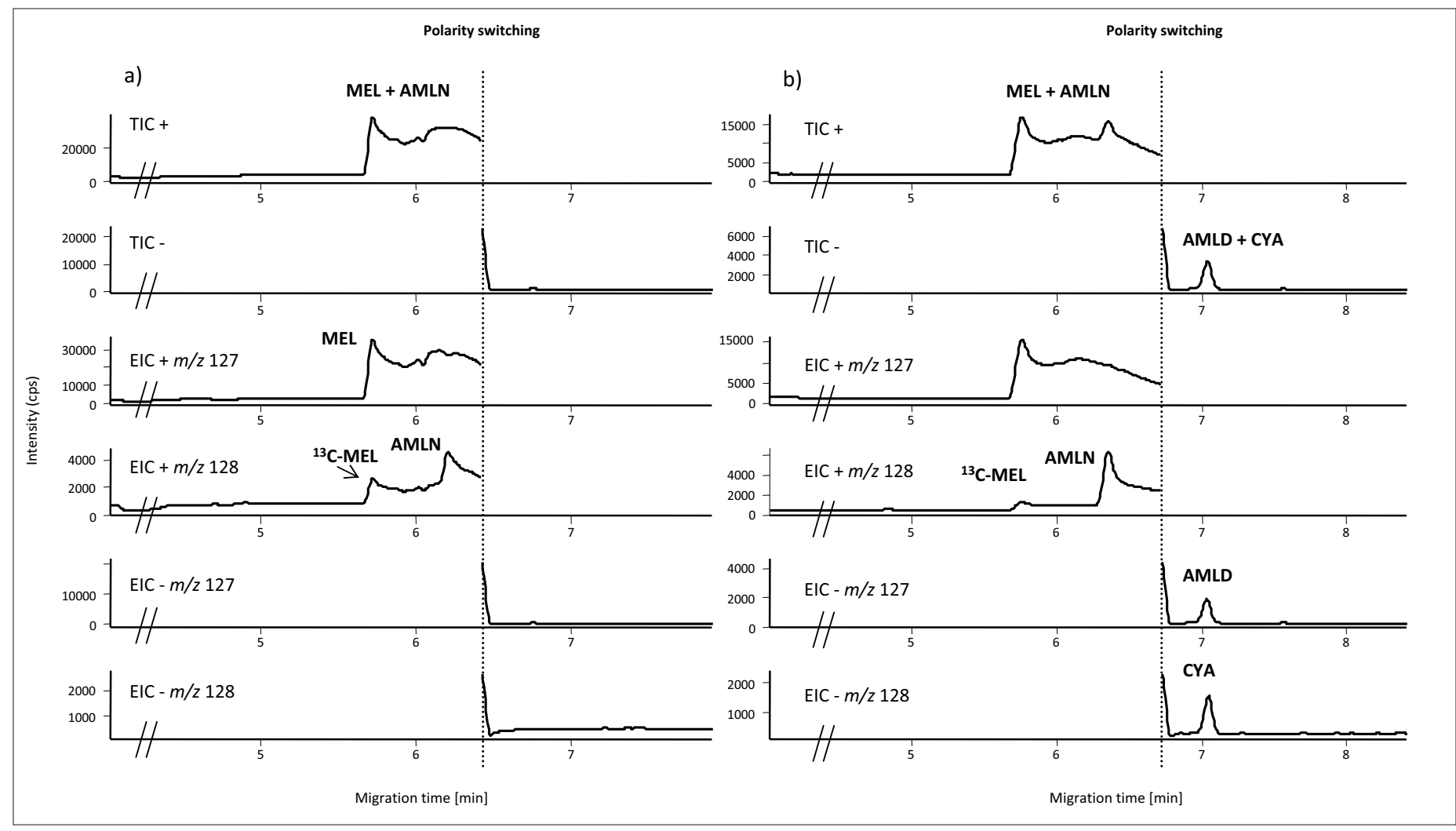

Fig. 5. a) CE-ESI-MS electropherograms obtained by injecting elution fraction after extraction with Strata Melamine cartridge of powdered Rapilait milk spiked with MEL, AMLN, AMLD at $5 \mathrm{ppm}$, and CYA at $1 \mathrm{ppm}$. ESI+ from 0 to $6.4 \mathrm{~min}$, switch of polarity at $6.4 \mathrm{~min}$ (300 ms), and ESI- from 6.7 to $8.4 \mathrm{~min}$. b) CE-ESI-MS electropherograms obtained by injecting elution fraction after extraction with Strata Melamine cartridge of standard solutions spiked with MEL, AMLN, AMLD, and CYA at $25 \mathrm{ppm}$. ESI+ from 0 to $6.7 \mathrm{~min}$, switch of polarity at $6.7 \mathrm{~min}$ (300 ms), and ESI- from 7.0 to $8.7 \mathrm{~min}$. See text for experimental conditions. 
at $25 \mathrm{ppm}$. At this concentration, electropherograms obtained for MEL and AMLN were still not satisfactory (Fig. 5b), while AMLD and CYA were present. Therefore, this material seemed sufficient to extract high concentrations of AMLD and CYA, but did not give adequate results for MEL and AMLN, in either standard solutions or spiked milk. Although operating conditions were investigated, in terms of i) cartridge conditioning, ii) loading step ( $\mathrm{pH}$ of the sample), iii) washing step (nature and proportion of solvent), iv) elution step (nature and volume of the solvent), and v) flow through the cartridge, no convincing or repeatable results were obtained, particularly for MEL and AMLN.

In a second set of experiments, Rapilait milk spiked with the four analogs was extracted with a strong cationic exchanger according to a protocol routinely used to extract only MEL from solid food product. The extracted sample was analyzed with the developed CE-ESI-MS method and the electropherograms are presented in Fig. 6a. MEL and AMLN were present on the electropherograms, while AMLD and CYA were absent, according to the selective retention mechanism of MCX material that could only retain cationic compounds, which were MEL and AMLN in this study. An S/N of 145 was obtained for MEL in spiked milk at $5 \mathrm{ppm}$. This result demon- strates the applicability of the developed CE-ESI-MS method for the analysis of contaminated samples, considering to the regulatory cut-offs of $1 \mathrm{ppm}$ in infant formula and $2.5 \mathrm{ppm}$ in other food products. Chinese reconstituted milk contaminated with MEL obtained from an interlaboratory study was also analyzed and showed presence of MEL on the electropherogram, while presence of AMLN was excluded (Fig. 6b). These results were confirmed by an LC-MS analysis performed at the Food Authority Control of Geneva (Geneva, Switzerland). AMLD and CYA, which were not extracted with this material due to the selective retention mechanism, could be extracted in a second step using mixed-mode anion exchanger (MAX) cartridges. ${ }^{[54]}$

\section{Conclusions}

The development of powerful analytical techniques in the context of food analysis is of prime importance. This was recently illustrated by dairy products adulteration with MEL, a nitrogen-rich compound that was illegally added to infant formulas, causing severe damage to the human urinary system. In this study, MEL and its by-products (AMLN, AMLD, and CYA) were analyzed within a single run with CE-ESI-MS. The method was applied to real samples, such as spiked blank powdered milk and contaminated powdered milk. With a $25 \mathrm{mM}$ (ionic strength) ammonium acetate BGE set at pH 5.2, MEL and AMLN migrated as cations in the first part of the run, and AMLD and CYA as anions in the second part. The unique feature of $\mathrm{CE}$ permitted the division of the run into two time segments for MS detection, enhancing sensitivity and data quality. To assist the simultaneous protonation of MEL and AMLN and the deprotonation of AMLD and CYA in the ESI source, 2\% ammonia was added to the sheath liquid composed of a mixture of water-iprOH $(50: 50, \mathrm{v} / \mathrm{v})$. With these conditions, all compounds could be resolved either by CE or by MS, and LOD down to $200 \mathrm{ppb}$ were reached. Two sample preparations were tested in spiked blank powdered milk and contaminated powdered milk. MCX cartridges allowed the extraction of MEL and AMLN, but not AMLD and CYA. A new material was also tested with a protocol developed by the manufacturer but peak shapes obtained for MEL and AMLN were not satisfactory, while AMLD and CYA could not be detected at a concentration lower than $10 \mathrm{ppm}$.

\section{List of Abbreviations \\ ACN Acetonitrile \\ AMLD Ammelide}

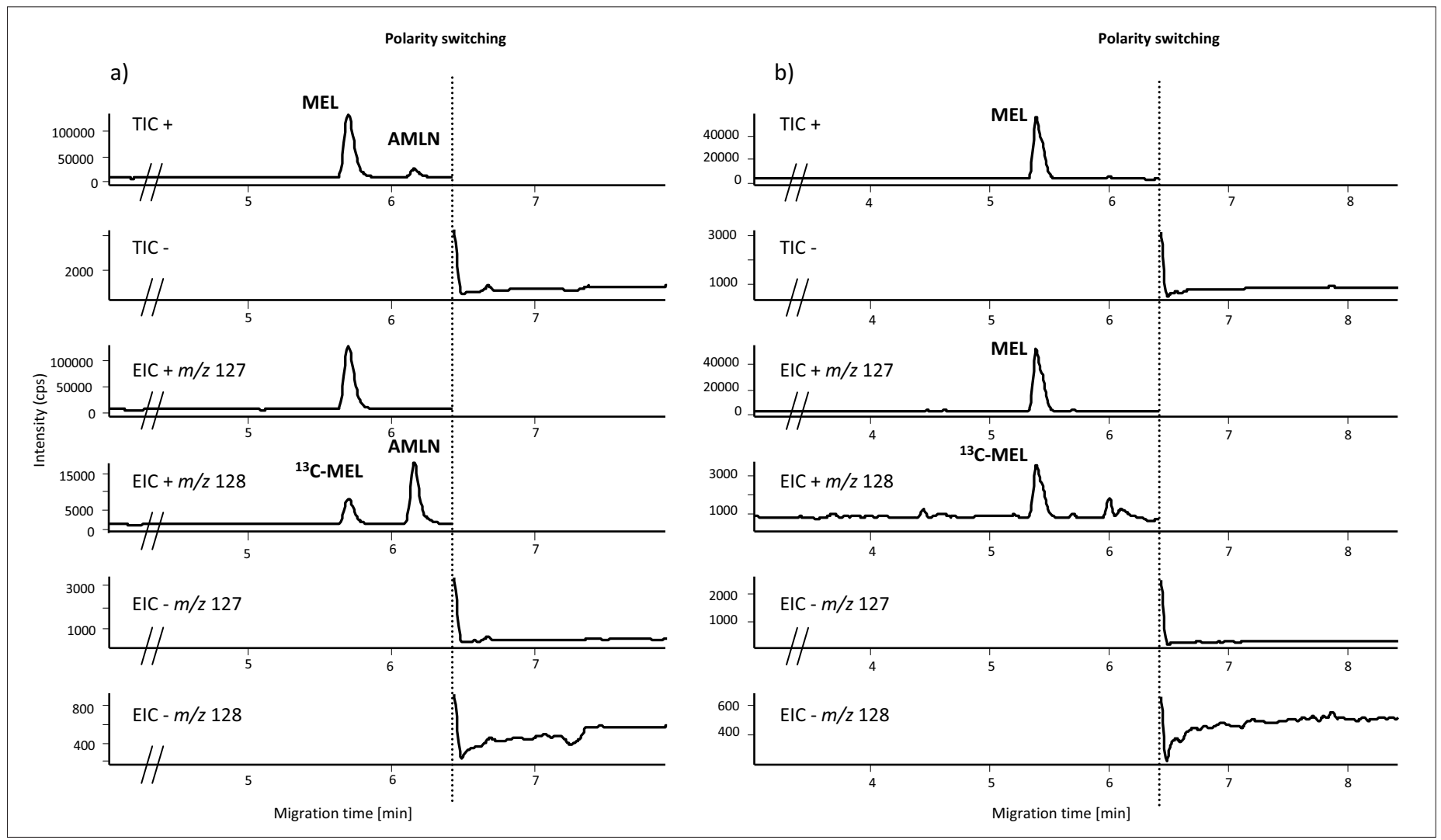

Fig. 6. a) CE-ESI-MS electropherograms obtained at pH 5.2 by injecting elution fraction after MCX extraction of powdered Rapilait milk spiked with MEL, AMLN, AMLD at $5 \mathrm{ppm}$, and CYA at $1 \mathrm{ppm}$. ESI+ from 0 to $6.4 \mathrm{~min}$, switch of polarity at $6.4 \mathrm{~min}$ (300 ms), and ESI- from 6.7 to $8.4 \mathrm{~min}$. b) CEESI-MS electropherograms obtained by injecting elution fraction after MCX extraction of contaminated powdered milk (interlaboratory study). ESI+ from 0 to $6.4 \mathrm{~min}$, switch of polarity at $6.4 \mathrm{~min}(300 \mathrm{~ms})$, and ESI- from 6.7 to $8 \mathrm{~min}$. See text for experimental conditions. 


$\begin{array}{ll}\text { AMLN } & \text { Ammeline } \\ \text { BGE } & \text { Background electrolyte } \\ \text { CYA } & \text { Cyanuric acid } \\ \text { DMF } & \text { N,N-dimethylformamide } \\ \text { EIC } & \text { Extracted ion current } \\ \text { ESI } & \text { Electrospray ionization } \\ \text { EtOH } & \text { Ethanol } \\ \text { FWHM } & \text { Full width at half maximum } \\ \text { iprOH } & \text { Isopropanol } \\ \text { LOD } & \text { Limit of detection } \\ \text { MEL } & \text { Melamine } \\ \text { MeOH } & \text { Methanol } \\ \text { m/z } & \text { Mass-to-charge ratio } \\ \text { NMF } & \text { N-methylformamide } \\ \text { SIM } & \text { Selected ion monitoring } \\ \text { SPE } & \text { Solid-phase extraction } \\ \text { TDI } & \text { Tolerable daily intake } \\ \text { TIC } & \text { Total ion current }\end{array}$

\section{Acknowledgements}

The authors wish to thank Dr Yveline Henchoz for the determination of $\mathrm{pK}_{\mathrm{a}}$ values; Josiane Prat for her technical assistance; Agnes Simon from Brechbühler AG (Prilly, Switzerland) for her technical support. The authors have declared no conflicts of interest.

Received: April 7, 2011

[1] World Health Organization/Food and Agriculture Organization of the United Nations, Expert Meeting to review Toxicological Aspects of Melamine and Cyanuric Acid, 2008, 1 .

[2] A. K. C Hau, T. H. Kwan, P. K. T Li, J. Am. Soc. Nephrol. 2009, 20, 245.

[3] E. E. Simanek, M. Mammen, D. M. Gordon, D. Chin, J. P. Mathias, C. T. Seto, G. M. Whitesides, Tetrahedron 1995, 51, 607.

[4] V. Bhalla, P. S. Grimm, G. M. Chertow, A. C. Pao, Kidney Int. 2009, 75, 774.

[5] Y. C. Tyan, M. H. Yang, S. B. Jong, C.K. Wang, J. Anal. Bioanal. Chem. 2009, 395, 729.

[6] E. A. Garber, J. Food Prot. 2008, 71, 590.

[7] B. Kim, L. B. Perkins, R. J. Bushway, S. Nesbit, T. Fan, R. Sheridan, V. Greene, J. AOAC Int. 2008, 91,408 .

[8] M. Lin, L. He, J. Awika, L. Yang, D.R. Ledoux H. Li, A. Mustapha, J. Food Sci. 2008, 73, T129.

[9] X. Zhu, S. Wang, Q. Liu, Q. Xu, S. Xu, H. Chen, J. Agric. Food Chem. 2009, 57, 11075.
[10] X. M. Xu, Y. P. Ren, Z. X. Cai, J. L. Han, B. F. Huang, Y. Zhu, Anal. Chim. Acta 2009, 650, 39.

[11] S. H. Tzing, W. H. Ding, J. Chromatogr. A 2010 , 1217, 6267.

[12] A. Desmarchelier, M. Guillamon Cuadra, T. Delatour, P. Mottier, J. Agric. Food Chem. 2009, 57, 7186.

[13] Y. T. Wu, C. M. Huang, C. C. Lin, W. A. Ho, L. C. Lin, T. F. Chiu, D. C. Tarng, C. H. Lin, T. H. Tsai, J. Chromatogr. A 2009, 1216, 7595.

[14] D. N. Heller, C. Nochetto, Rapid Commun. Mass Spectrom. 2008, 22, 3624.

[15] W. C. Andersen, S. B. Turnispeed, C. M. Karbiwnyk, S. B. Clark, M. R. Madson, C. M. Gieseker, R. A. Miller, N. G. Rummel, R. Reimschuessel, J. Agric. Food Chem. 2008, 56, 4340.

[16] R. Muñiz-Valencia, S. G. Ceballos-Magaña, D. Rosales-Martinez, R. Gonzalo-Lumbreras, A. Santos-Montes, A. Cubedo-FernandezTrapiella, R. C. Izquierdo-Hornillos, Anal. Bioanal. Chem. 2008, 392, 523.

[17] A. M. Rodriguez Mondal, A. Desmarchelier, E. Konings, R. Acheson-Shalom, T. Delatour, J. Agric. Food Chem. 2010, 58, 11574

[18] M. Zhang, S. Li, C. Yu, G. Liu, J. Jia, C. Lu, J. He, Y. Ma, J. Zhu, C. Yu, J. Chromatogr. A 2010, 878, 758 .

[19] Y. Xu, L. Chen, H. Wang, X. Zhang, Q. Zeng, H. Lu, L. Sun, Q. Zhao, L. Ding, Anal. Chim. Acta 2010, 661, 35 .

[20] L. Chen, Q. Zeng, X. Du, X. Sun, X. Zhang, Y. Xu, A. Yu, H. Zhang, L. Ding, Anal. Bioanal. Chem. 2009, 395, 1533.

[21] H. Miao, S. Fan, Y. N. Wu, L. Zhang, P. P. Zhou, J. G. Li, H. J. Chen. Y. F. Zhao, Biomed. Environ. Sci. 2009, 22, 87.

[22] M. S. Filigenzi, B. Puschner, L. S. Aston, R. H. Poppenga, J. Agric. Food Chem. 2008, 56, 7593.

[23] S. Ehling, S. Tefera, I. P. Ho, Food Addit. Contam. 2007, 24, 1319.

[24] H. Yu, Y. Tao, D. Chen, Y. Wang, Z. Liu, Y. Pan, L. Huang, D. Peng, M. Dai, Z. Liu, Z. Yuan, Anal. Chim. Acta 2010, 682, 48.

[25] N. Yan, L. Zhou, Z. Zhu, X. Chen, J. Agric. Food Chem. 2009, 57, 807.

[26] H. A. Cook, C. W. Klampfl, W. Buchberger, Electrophoresis 2005, 26, 1576.

[27] C. W. Klampfl, L. Andersen, M. Haunschmidt, M. Himmelsbach, W. Buchberger, Electrophoresis 2009, 30, 1.

[28] J. Xia, N. Zhou, Y. Liu, B. Chen, Y. Wu, S. Yao, Food Control 2010, 21, 912.
[29] Y. Jin, L. Meng, M. Li, Z. Zhu, Electrophoresis 2010, 31, 3913.

[30] H. Sun, N. Liu, L. Wang, Y. Wu, Electrophoresis 2010, 31, 2236.

[31] C. W. Chang, S. P., Chu, W. L. Tseng, J. Chromatogr. A 2010, 1217, 7800.

[32] Y. Wen, H. Liu, P. Han, Y. Gao, F. Luan, X. Li, J. Sci. Food Agric. 2010, 90, 2178.

[33] L. Meng, G. Shen, X. Hou, L. Wang, Chromatographia 2009, 70, 991.

[34] Z. Chen, X. Yan, J. Agric. Food Chem. 2009, 57, 8742.

[35] C. W. Klampfl, Electrophoresis 2006, 27, 3 .

[36] J. Schappler, D. Guillarme, J. Prat, J. L. Veuthey, S. Rudaz, Electrophoresis 2007, 28, 3078.

[37] J. Schappler, J. L. Veuthey, S. Rudaz, Separation Sci. Technol. 2008, 9, 477.

[38] E. J. Maxwell, D. D. Chen, Anal. Chim. Acta 2008, 627, 25 .

[39] P. Pantuckova, P. Gebauer, P. Bocek, L. Krivankova, Electrophoresis 2009, 30, 203.

[40] P. Kubáń, P. Kubáń, V. Kubáń, J. Chromatogr. A 1999, 75.

[41] C. L. Lin, C. J. Yu, Y. M. Chen, H. C. Chang, W. L. Tseng, J. Chromatogr. A 2007, 219.

[42] M. Mokkadem, A. Varenne, J. E. Belgaied, C. Factor, P. Gareil, Electrophoresis 2007, 28, 3070.

[43] P. Kubáń, , B. Karlberg, Anal. Chem. 1998, 70, 360.

[44] K. Hopper, H. LeClair, B. R. McCord, Talanta 2005, 67, 304.

[45] A. Padarauskas, Anal. Bioanal. Chem. 2006 , $384,132$.

[46] F. Priego-Capote, M. D. Luque de Castro, Electrophoresis 2005, 26, 2283.

[47] I. L. Tsai, S. W. Sun, H. W. Liao, S. C. Lin, C. H. Kuo, J. Chromatogr. A 2009, 1216, 8296.

[48] L. Geiser, S. Rudaz, J. L. Veuthey, Electrophoresis 2003, 24, 3049.

[49] L. Geiser, Y. Henchoz, A. Galland, P. A. Carrupt, J. L. Veuthey, J. Sep. Sci. 2005, 28, 2374.

[50] L. Geiser, J. L. Veuthey, Electrophoresis 2007, $28,45$.

[51] A. Staub, J. Schappler, S. Rudaz, J. L. Veuthey, Electrophoresis 2009, 30, 1610.

[52] S. Zhou, K. D. Cook, J. Am. Soc. Mass Spectrom. 2000, 11, 961 .

[53] J. Schappler, R. Nicoli, D. Nguyen, S. Rudaz, J. L. Veuthey, D. Guillarme, Talanta 2009, 78 , 377.

[54] H. P. O. Tang, S. S. L. Lai, A. Y. H Lai, W. O. Lee, Chromatographia 2009, 70, 1405. 